\title{
The Effects of Uncertainty Avoidance on Brand Performance: Marketing Creativity, Product Innovation and the Brand Duration
}

\author{
Marco S. Giarratana \\ Universidad Carlos III de Madrid \\ marco.giarratana@uc3m.es
}

\author{
Anna Torres \\ Universitat Pompeu Fabra \\ anna.torres@upf.edu
}

\begin{abstract}
This paper investigates the link between brand performance and cultural primes in high-risk, innovation-based sectors. In theory section, we propose that the level of cultural uncertainty avoidance embedded in a firm determine its marketing creativity by increasing the complexity and the broadness of a brand. It determines also the rate of firm product innovations. Marketing creativity and product innovation influence finally the firm marketing performance. Empirically, we study trademarked promotion in the Software Security Industry (SSI). Our sample consists of 87 firms that are active in SSI from 11 countries in the period 1993-2000. We use the data coming from SSI-related trademarks registered by these firms, ending up with 2,911 SSI-related trademarks and a panel of 18,213 observations. We estimate a two stage model in which first we predict the complexity and the broadness of a trademark as a measure of marketing creativity and the rate of product innovations. Among several control variables, our variable of theoretical interest is the Hofstede's uncertainty avoidance cultural index. Then, we estimate the trademark duration with a hazard model using the predicted complexity and broadness as well as the rate of product innovations, along with the same control variables. Our evidence confirms that the cultural avoidance affects the duration of the trademarks through the firm marketing creativity and product innovation.
\end{abstract}

Key words : Trademark duration, creativity, uncertainty avoidance cultural index.

JEL code : M31. 


\section{Introduction}

Creativity as an antecedent of innovation is studied, either as conductor of product innovation (Spickett-Jones, 2003), or as a source of marketing promotions for mature products (Andrews and Smith, 1996). The same concept of creativity also appears in studies related on the demand side: customer innovation adoption is subjective and cultural dependent (Steenkamp et al., 1999). However, while in the consumer field of analysis it is common to consider explicitly the effects of cultural dimensions (Hofstede, 1991), on the supply side the research on creativity and cultural dimensions mainly focuses on how managers organize and exploit the collaborations between the R\&D and Marketing departments (Andrews and Smith, 1996; Sethi et al., 2001). Some scholars also analyze the relationship between cultural traits and firm propensity to innovate (Shane, 1993). However, the literature scarcely highlights the potential link with antecedents of the firm marketing creativity.

This article aims to advance evidence on this trajectory. Previous research measures marketing creativity from direct interviews with managers, with evident limitations in terms of respondent biases (Andrews and Smith, 1996). Indeed, since literature defines creativity as a novel and meaningful work (Stein, 1953; Im et al, 2004), we capture creativity by the complexity and broadness of a new brand. In fact, in a high level of involvement product category (Harris, 1987) all the dimensions of customer-based brand equity, brand awareness and brand image, are relevant for purchase decisions (Keller, 1993). Complexity increases brand awareness, which is the first step to create brand equity: as the number of elements that include the brand increase (more complexity), it is easier that customers will evoke the brand, as the number of cues increase. On the other hand, broadness becomes a signal of potentialities in terms of brand extensions. A broad trademark corresponds to a brand which can be stretched to several categories. Several authors (e.g. Dacin and Smith, 1994) recognize that the important dimensions to achieve a successful brand extension are specific brand associations and a strong quality along time, both categories being related with the brand image (Broniarczyk and Alba, 1994). To get such quality along time, a high level of marketing creativity is required.

Our test-bed is the Software Security Industry (SSI), a recent software market where product and marketing strategies play a pivotal role (Fosfuri and Giarratana, 2007). Analyzing all the SSI-related brands of a representative sample of 87 firms that own more than $70 \%$ of the SSI market, we estimate a two stage model in which first we predict the determinants of the complexity and the broadness of a brand, as well as of firm rate of product innovation, and then we estimate the brand duration with a hazard model using the predicted complexity, 
broadness and rate of product innovation, along with firm control variables and cultural indices.

In so doing, we proxy marketing creativity with an objectively measured variable: the complexity and the broadness of a registered trademark. We utilize the trademark duration as a measure of marketing performance, since a more creative (new and meaningful) brand should last more. We investigate the link between trademark duration and cultural primes using the marketing creativity of the firm as a mediator effect. We first test whether cultural dimensions determine the marketing creativity of a firm, and then we explore whether the creativity affects the duration of a trademark. We control also for the effect that the cultural primes could have on the product innovation strategy of the firm.

Given the risky nature of this software market, characterized by short-product life cycle, hyper-competitive dynamics and high rate of firm entry and exit, we draw our research interest into a particular cultural feature: the uncertainty avoidance cultural dimension (Hofstede, 1991). This is because high turbulent environments throw to central stage the high risks that firms bear in taking the strategic decisions under uncertainty. Results are in line with the theory proposed and show that uncertainty avoidance affects the marketing creativity and then creativity affects the duration of a brand.

The paper is organized as follows. The next section presents the hypothesis developing. Section 3 illustrates the empirical exercises. Section 4 concludes.

\section{Theory \& Hypotheses}

Several scholars consider how cultural factors influence the process of new product creation as well as the ir related marketing activities. Shane (1992; 1993) establishes the connection between Hofstede's uncertainty avoidance index and firm innovation measured with patent applications. He finds a significant negative association between uncertainty avoidance and patented innovation.

Nakata \& Sivakumar (1996), in a theoretical paper, connect national cultures and new product development, differentiating the effect of Hofstedes' cultural indices in the initial phase of the product development vis-á-vis the implementation phase. In agreement with Shane, they suggest that low levels of uncertainty avoidance facilitate the initiation phase of new product development through risk taking and minimal planning and control. However, they go one step further and suggest also how high levels of uncertainty avoidance can facilitate implementation of product development since risk aversion increases tight planning and controls. 
Recently, some contributions (Andriopolous and Gotsi, 2000; Sethi et al., 2001) highlight the importance of the relationship between the antecedents of creativity and new consumer products. Even if these scholars confine the antecedents of creativity inside marketing programs related to mature products (Andrews and Smith, 1996), they highlight how the inter- and intra- department relationships, influence creativity. In another contribution, Im and Workman, (2004) discuss the relationship between creativity and cultural traits but they do not specify antecedents of creativity, only testing the relationship between market orientation as antecedent of creativity construct.

Sethi et al. (2001) propose a model that tests the relevant conditions that allow creativity to foster new consumer products like positive correlation between super-ordinate identity and creativity, negative association between social cohesion and creativity, and positive effect between encouragement to take risk and creativity. Moreover, Andrews and Smith (1996) stress that risk taking attitudes of firms have a positive impact on marketing program creativity, in a context of promotion over mature products. Risk adverse individuals use to work under algorithmic processes (Andrews and Smith, 1996; Sethi et al 2001) compared to heuristic ones, because consolidated routines help to solve problems with lowering the variance on the expected event.

Granted this, the cultural index that should largely influence the firm marketing creativity, especially in the case of high-risky innovation-based sectors, is uncertainty avoidance index (UAI) (Hofstede, 1991; Shane, 1993). Several references (e.g. Andrews and Smith, 1996) define marketing activities as tools to protect/differentiate the firm products. Our premise is that under such hyper-competitive environmental conditions, the UAI is a fundamental determinant of a firm marketing relevance and performance.

The definition of marketing creativity as something meaningful and new (Im et al., 2004) leads to consider as one of its most direct measures the broadness and the complexity of a new brand. Indeed, since a new brand is the natural outcome of a process of marketing creativity, the intrinsic characteristics of the brand should set the level of the underling creativity. According to Mendoza et al. (2004), complexity corresponds to the combination of words, slogans, letters and numerals; drawings and symbols, three-dimensional signs such as the shape and packaging of goods, audible signs such as music or fragrances, colors and holograms. Broadness refers to the number of alternative product categories on which a brand could be potentially applied, extended, and protected. Our claim is that the different levels of UAI should affect these two important dimensions of a new brand, its broadness and complexity, that define its level of marketing creativity and therefore its life duration. It is 
widely accepted that brands generated by higher creativity process tend to give competitive advantage to the firm (Andrews and Smith, 1996) like creating brands that last more.

There are different reasons that shape the relation between higher levels of UAI and higher levels of brand complexity. In one hand, higher levels of UAI lead firms to protect/differentiate more their new brands to face the threats of the competitors. Therefore, they will produce more complex trademarks to avoid imitation, reducing the risk of loosing market share or segment loyalty not recovering the realized investments. On the other hand, higher brand complexity, based on elements which become new and meaningful for the targeted consumers, increases the level of brand awareness due to a higher number of cues. This will foster a more rapid exploitation of the R\&D and marketing investments. Meaningful brand complexity increases the brand awareness and then, with repeated expositions, the memory stock of the consumers. Consumers, under particular conditions, can then purchase the product without comparisons between alternatives (Keller, 1993), reducing the costumers' search costs and the time elapsed between the actual purchase and the arrival of the product on the shelf. If brand image evaluations drive the customer purchases, then, higher meaningful complexity increases brand awareness which increases the probability that a brand will the subject (i.e. the starting point) in a purchase process. According to Tversky (1977) a product or brand could exploit benefits when it serves as a focalpoint of comparison, since people tend to use its unique features as a type of checklist in judgments.

This line of reasoning lead to our first hypothesis:

Hp1. In innovation-based sectors, the higher the level of uncertainty avoidance of the culture embedded in a firm, the more is the complexity of its brands.

Higher broadness of the trademark increases its protection, so that firms with higher UAI cultures should prefer broader trademark. In fact, broader brands build fences against other firms which could damage the image and the reputation by using the brands in antagonist or unrelated categories (Keller, 1993). Moreover, according to Hofstede (1991) higher UAI cultures tend to manifest more emotional attitudes. Then, also in terms of brand positioning and creation, higher UAI cultures are biased towards emotional arguments. This idea is tested in advertising literature by Ramaprasad and Hasegawa (1990) who find that the high UAI culture uses more emotional than rational arguments in positioning brands on TV advertising. On the same line, Hong et al. (1987) and Lin (1993) points out that high UAI creativity 
strategies reinforce company reputation and image using emotional arguments. As a matter of facts, high UAI cultures tend to create more general and abstract brands that appeal to really universal meanings that could be easily extendible to several product categories.

Then, our second hypothesis proposes that:

Hp2. In innovation-based sectors, the higher the level of uncertainty avoidance of the culture embedded in a firm, the broader its brands.

Marketing mix activities collect instruments related with price, product, distribution and communications, all of them interrelated. Brands, therefore, include elements of different dimensions. Product innovation strategy is naturally the most complementary activity of the firm marketing creativity. The literature is absolutely concord on this point: countries with higher levels of UAI tend to be less product innovators, given that product innovation is a risky activity that generates uncertainty and requires important investments (e.g. Shane, 1993).

Therefore, our third hypothesis reads:

H3: In innovation-based sectors, the higher the level of uncertainty avoidance of a culture, the less the rate of firm product innovation.

Granted the previous three hypotheses, we could propose a more general one. Marketing creativity, through brand broadness and complexity, should increase the life expectancies of a brand since they increase the brand power and awareness. The rate of product innovation reduces stretch-ability of a brand, since the hyper-competitive introduction of new products implies a potential need for new brands and images. Indeed, while it is possible to extend existing brands on new versions of existing products, it is difficult to use old names, logos and advertising on radical new products. Therefore, the rate of product innovations should negatively affect the life duration of a brand. To conclude, the previous three hypotheses will affect the marketing performance in the following way:

H4: In innovation-based sectors, the higher the level of uncertainty avoidance, the longer the life of a brand, mediated by an increase in marketing creativity (through a positive effect on brand complexity and broadness) and a decrease in the rate of product innovation. 
Figure 1 summarized the proposed theoretical contribution:

[Insert Figure 1 about here]

\section{Methodology and results}

\subsection{The industry and the sample}

We study the determinants of brand duration in the Software Security Industry (SSI). SSI is a relatively recent segment of the software industry, and constitutes a quintessential example of a hyper-competitive environment in which product and marketing strategies foster firm survival and performance (Fosfuri and Giarratana, 2007). The SSI has experienced an unprecedented growth in recent years. The world market for the SSI reached USD 4.4 billon in 1999; up from USD 3.2 billion in 1998 and USD 2.2 billion in 1997. In 1999, the US market alone accounted for about $70 \%$ of world revenues in the SSI (International Data Corporation 1999). The technological foundation of the industry dates back to the late 70s, when the US government channeled important investments in military projects linked to the security of data transmission. However, it was not until the late $80 \mathrm{~s}$ that commercial versions of software security products were released into the civilian market. The inception of the industry therefore coincided with the growing market for home personal computers and the development of the Internet. This, in turn, created a growing commercial demand with different requirements that broadened the spectrum and complexity of the required products and services. Specifically, the first software security products were the antivirus packages at the end of the 1980s. To date, the SSI includes a wide range of products: from basic security software, such as Virtual Private Networks, Firewall and Virus Scanning to advanced security services like Public Key Infrastructures, Security Certification and Penetration Testing.

In SSI advertising and brands are clearly important, especially in terms of security and reliability reputation. This is well expressed by the words of Scott Kozar, sales executive for IBM, "many times, in security software, customers are brand driven" (ENT, 2001). For example Check Point, the Israeli world leader in Firewalls, "has meme recognition among everyone [...] people buying a security solution think they can't go wrong buying Check Point. It has a lot of mind share out there". (Computer Reseller News, 2001).

We built our sample from the LECG Corptech Patent database (www.lecg.com), which covers about 80,000 software patents granted by USPTO from 1976 to 2000 . We selected all the patents in the US technological classes 380 ("Cryptology") and 705, 
subclasses 50-79 ("Business Processing Using Cryptography"). We then combined this information with the SSI Database constructed by Giarratana (2004) which includes all the SSI product introductions. The original data source is the database Gale Group's Infotrac Promt (www.gale.com), which is the new version of Predicast database, used in several research articles (e.g. Pennings and Harianto, 1992). Promt contains comprehensive and reliable coverage of companies, products, markets, alliances, and deals from a vast collection of journals, newsletters, news releases and newspapers. We constructed our database from firm news announcements in Promt classified under SIC code 73726, which corresponds exactly to Software Security, and under the firm events "New Product Announcement". We ended up with a sample of 87 firms. This sample consists of 87 firms with at least a patented technology and a released product that are active in SSI from 11 countries in the period 19932000. The two requirements, patent and product, are necessary to single out firms with R\&D investment in the industry and that also exploit innovations in downstream markets with final products. This sample accounts for more than $70 \%$ of the revenues of the SSI world market (Hoover's data).

\subsection{Empirical strategy and dependent variables}

We opt for a two stage estimation to avoid potential endogeneity effects. First, we estimate three equations that test hypotheses 1 to 3 . Then, we insert the predicted value of these three equations in a final regression that test the fourth hypothesis. Therefore, we have four equations and four different dependent variables in total.

Brand complexity. The first dependent variable is related to the level of brand complexity. We use US trademark data, since the US Patent \& Trademark Office (USPTO) represents the world most important office for brand protection especially for software. First we select all the SSI-related trademarks registered by these firms in the sample period ending up with 2,911 trademarks ${ }^{1}$. Trademarks are combinations of "words, phrases, symbols or designs that identify and distinguish the source of the goods or services" (USPTO Documentation, http://tess.uspto.gov). Firms can register as a trademark a new name, a jingle or a slogan, a new image, or a logo. They secure in this way legal protection of their investment in marketing, reputation for quality, and brand names. Trademarks can protect not only the name and the logo of a product, but also promotions. "Act! Pak!", "Work virtually

\footnotetext{
${ }^{1}$ We select all the software trademarks of these firms that in the descriptions of the brand include the words "security", "antivirus", "protection", "reliability", "firewall". We also include all the software trademarks that could be in same way extended to SSI products. In so doing, we exclude all the software trademarks that refer to no-SSI products. This was an easy work for firm specialized in SSI, more complicated in the case of large diversified firms.
} 
everywhere" and "Safe on the web!" are all trademarks registered by Symantec, one of the world leaders in antivirus packages.

Trademarks are classified by their level of complexity, with seven different codes that indicate the type of mark drawing, from simple drawing to music and sound. Since about the $60 \%$ of all trademarks registered is classified with the simplest code ("type drawing") (see USPTO manual, www.uspto.gov), we create a dummy variable that is 0 if the trademark is classified as the code "type drawing" -the simplest -, 1 otherwise. The model used to estimate this dependent variable is a logit model.

Brand broadness. The second hypothesis asks for some measures of brand broadness. Trademark owners pay different types of fees for each class of goods/services for which a trademark is registered and protected, and they have to prove periodically that they are using the trademark in the relevant market; even if the owner is willing to pay the fees, a trademark is cancelled if it is not commercially used for five consecutive years after registration. Therefore, for each trademark there is important information available: for how many different product categories the owner has asked and paid for brand protection. The total potential sectors are 60 , however about $50 \%$ of trademarks are protected in less than four product categories (see USPTO manual, www.uspto.gov). Therefore we create a dummy variable that is 0 if the trademark is protected in less than 4 product categories $(1,2$, or 3$), 1$ if it is protected in at least 4 product categories (4, 5, 6 and more). We estimate this dependent variable with a logit model.

Product innovations. To proxy firm product innovations, we use the SSI database constructed by Giarratana (2004) which includes all the SSI product introductions. We count the number of all firm product introductions that refer to new products. This means that we do not count new versions of existing products. For example, the release of the version 2.1 of Dr Norton security system is not included. Being a count data variable, we will estimate a negative binomial model.

Brand duration. For each trademarks we could extract the information of the year in which the brand was dismissed, if cancelled. Therefore, we use the life of trademark as a proxy of promotion performance, and we estimate a piecewise exponential Hazard model that predict the trademark probability to be dismissed.

\subsection{Independent variables}

Our variable of theoretical interest aimed to explain creativity is Uncertainty Avoidance cultural Index (UAI) (Hofstede, 1991). We download the variable values for each country directly from Hofstede's web site (http://www.geert-hofstede.com/). "UAI deals with a 
society's tolerance for uncertainty and ambiguity; [...] It indicates to what extent a culture programs its members to feel either uncomfortable or comfortable in unstructured situations". High levels of UAI picture generally more risk adverse societies. We attach to each firm the corresponding UAI for its country.

As exogenous variables we use several firm controls like firm fixed assets and age as a proxy of size and experience, firm marketing expenditure intensity (marketing expenditures over sales), firm $R \& D$ expenditure intensity ( $\& \& D$ expenditures over sales), country dummies and the trademark years of life. Financial variables are from SEC filings and Bureau Van Dijk's datasets Jade (Asia), Amadeus (Europa) and Icarus (USA). Except dummies, all variables are time variant. In the regression, to lower even more collinearity problems the variables are inserted in log values. Table 1 shows basic descriptive statistics.

[Insert Table 1 about here]

\subsection{Results}

All the Tables of results propose a first Model that omits the core covariate, showing only the baseline model with the control variables. Then, the following models progressively add our covariates of interest. Table 2 shows Logit regressions predicting brand broadness and complexity. Our hypotheses gain support from data. Firms in countries with higher levels of UAI tend to produce more complex and broad brands (Hp1 and Hp2). The coefficient for complexity is significant and it has the expected $\operatorname{sign}(\beta=7,631, t=0,746, p<0,05)$. UAI has a similar magnitude effect on broadness. It is also significant with the expected $\operatorname{sign}(\beta=7,039, t=0,674 p<0,05)$. The controls are also in line with the expected effects. Higher marketing intensity leads to more complex and broader brands. Old firms tend to have broader and less complex brand, probability the effect of reputation and umbrella branding. Firm size does not lead to robust results.

[Insert Table 2 about here]

The negative binomial regression in Table 3 displays a significant negative relationship between UAI and the number of new products released by the firm during the sample period $(\beta=-8,251, t=3,547 p<0,05)$. This result gives support to our third hypothesis and it confirms the findings of previous literature (i.e. Shane, 1993). The controls are also in line with all the previous literature on innovation. Size and R\&D intensity favor innovation, while 
the firm age tend to slow down the rate of product introductions (see for example Henderson, 1993)

[Insert Table 3 about here]

Our final estimation is a Hazard model that predicts the probability of dismissing a brand. Table 4 presents the results. We insert the predicted values of brand complexity, brand broadness and rate of new product introductions derived from the previous equations as covariates. Our fourth hypothesis states that the higher the level of UAI, the longer will be the life duration of a brand, being this effect mediated by an increase of marketing creativity, through brand complexity and broadness, and a decrease in product innovation rates. The results in Table 4 give support to this hypothesis, displaying significant coefficients with the expected signs. Predicted brand broadness and complexity increase the life of a trademark, with a higher magnitude of broadness over complexity $\left(\beta_{\text {PBroadness }}=-0,337, t=0,055, p<0,05 ; \beta_{\text {PComplexiy }}=-0,260, t=0,062, p<0,05\right)$. Finally, an increase in the level of product innovation decreases the life of the trademark $(\beta=0,266, t=0,176, p<0,05)$. This coefficient $\dot{s}$ similar to the previous one in magnitude but with opposite sign. Then, in global terms, firms with high levels of UAI tend to compete in high-tech competitive sectors through marketing creativity that spurs an increase in the life of its trademarks. Note that UAI is also significant beyond the effect of country dummies.

[Insert Table 4 about here]

\subsection{Some anecdotic evidence}

As a way to check the validity of our results, we actually look for advertising of software security products in the last number of PC World, and PC actual ones of the world most diffuse specialized journals for computer and software products. The intent is to build up some anecdotic evidence that could confirm some of our results and theories.

We find five advertising pages that we could clearly classified as an advertising of a security software product. Three are related to products released by two US firms, and four by no-US firm, two European (Spain and Germany), one from East Europe (Slovakia) and one 
Asian (South Korea) ${ }^{2}$. The two US firm adverting pages show plainly a tendency to propose rational arguments. In the first page there is the picture of a confident man on the left, on the right the name of the company with the logo "proven security" and the picture of an hardware part, in the center the words "the sentinel of your network" and at the bottom a series of explanations of the potential products applications. The second US advertising shows four pictures of men and women at work that represent four different products: antivirus, firewalls, spamkillers and privacy services. In the middle there is the slogan "protect your digital life from the first day" and at the bottom the technical features of the products.

The non-US advertising pages contain more emotional message. It is worth noting also the generality of the message. In the first one, from an Asian firm (South Korea), there is the drawing of a big traffic light with the red light on and big announcement in the middle of the page that says "Red Stop Virus". Then the phrase "the first security rule facing a virus is the common sense". In the bottom part the photo of two products with their prices. From an European firm (Spanish example), again the use of the combination of red/green colors, with the traffic light meanings. The announcement is the following: In red color: "Red light for the threat". In green color: "Green light for you". In the picture there is a man, with a red pullover, checking his computer. Behind him, there is a green tent protecting him. Bellow the page, the main benefits of this antivirus. The other European example, corresponding to Germany, has the following description. At the top of the page there is a picture of several umbrellas under a heavy rain. Then the message "Protect yourself". Then at the bottom of the page, there is a picture of the product and the detailed explanations of its features. Finally, an example that corresponds to a Slovakia firm ${ }^{3}$. In this advertisement, there are 3 drawings. A big eye in the center and two animals. One eagle, symbolizing the benefit of being the best in detecting, and a cheetah, representing the attitude to be the fastest in exploration.

\section{Conclusions and discussions}

This article analyzes the relationship between a culture attribute, precisely the Hofstede's uncertainty avoidance index (UAI), and the marketing creativity of firms competing in highrisk, innovation-based sectors. While previous literature (Shane, 1993) shows the negative effect that high levels of UAI has on firm product innovation propensity, we postulate that

\footnotetext{
2 We avoid intentionally mentioning the names of the companies. Photocopies of advertising pages are available on request.

3 If there is no Hoftsede's UAI index value for Slovakia, all countries corresponding to that regions have high UAI values, around 80 (Poland, Hungry, Czech Republic).
} 
high levels of UAI in a high-tech competitive sector will favor the marketing creativity, fostering the duration of a brand.

Empirically, we analyze brand duration for a representative sample of firms in an innovation-based sector like the Software Security Industry (SSI), using data on SSI-related trademarks. Our data support the conjecture that high levels of UAI foster the broadness and complexity of a brand, and reduce the pace of product innovation. These three effects impact positively the life duration of a brand. In other words, we find that firms embedded in culture with higher level of UAI tend to produce more complex and broad brands and less frequent new radical products.

Our findings have several managerial implications. A first suggestion relates to human resource management, particularly on the composition of the $R \& D$ and marketing departments. We show that the cultural traits could influence the strategic R\&D and marketing approach of a firm, since low UAI firms will be more oriented toward an intense product innovation while high UAI firms will focus on few products and more durable brands. Therefore, given the success path in a particular market, the cultural composition of the departments should be organized consequently. These results are also supported by Basset-Jones (2005).

A second interesting point is related directly to firms embedded in high UAI culture. If traditionally the literature points out the disadvantages that these firms could suffer in innovation-based sectors, our finding proposes a useful complementary avenue. While these firms may suffer a competitive weakness in terms of product innovations (Shane, 1993), they own a counterbalancing tool represented by the ir marketing investments. They could adopt a policy of increasing their efforts to consolidate the power and stretch-ability of a brand. This strategy could be traduced in low-risk investments in $R \& D$, for example focusing on a product versioning (i.e. new versions of existing products) and, at the same time, in fostering the marketing efforts directed in creating long lasting brands, stretched with horizontal or vertical extensions (Pitta and Katsanis, 1995).

Our article makes also advances in the measurement field. This is one of the first works that use directly data from trademarks registered by firms. Given that the main empirical data source in this field of research comes usually from direct surveys to managers, trademarks broaden and enrich the empirical potentials. Indeed, this represents a new field of analysis that clearly calls for advancements in different trajectories. The most direct example is clearly related to test whether our theory also applies in more mature product categories. 


\section{References}

Andrews, J. and Smith, D. C. (1996). In Search of the Marketing Imagination: Factors Affecting the Creativity of Marketing Programs for Mature Products. Journal of Marketing Research, 33, 174-187.

Andriopolous, C. and Gotsi, M. (2000). Benchmarking brand management in the creative industry. Benchmarking: An International Journal, 7, 7, 360-372.

Basset-Jones, N. (2005). The paradox of diversity management, creativity and innovation. Diversity Management, Creativity and Innovation, 14, 2.

Broniarczyk, S.M. and Alba, J.W. (1994). The importance of the brand in brand extension. Journal of Marketing Research, 31,2, 214-228.

Computer Reseller News. 2001. Check Point's Name Recognition. June 11, 4(2): 54

Dacin, P.A., Smith, D.C. (1994), The effect of brand portfolio characteristics on consumer evaluations of brand extensions, Journal of Marketing Research, Vol. 31 pp.229-42.

ENT. 2001. ASP-One Implements Windows 2000 SAN. March 26, 6 (3): 12

Fosfuri A. and Giarratana MS. (2007). Product Strategies and Survival in Schumpeterian Environments: Evidence from the Security Software Industry, Organization Studies, forthcoming

Harris, G. (1987). The implications of Low-involvement Theory for Advertising Effectiveness. International Journal of Advertising, 6, 207-221.

Henderson, R. (1993): Underinvestment and Incompetence as Responses to Radical Innovation: Evidence from the Photolithographic Alignment Equipment Industry, RAND Journal of Economics, 24 (2), 248-70.

Hofstede, G. 1991. Cultures and organizations. London: McGraw-Hill.

Hong, J.W., Muderrisoglu, A. and Zinkhan G.M. (1987). Cultural differences and advertising expression: A comparative content analysis of Japanese and U.S. magazine advertising. Journal of Advertising, 16, 1, pp. 55-62.

Im, S. and Workman, J.P. Jr. (2004). Market Orientation, Creativity, and New Product Performance in High-Technology Firms. Journal of Marketing, 68, 114-132.

Keller, K.L. (1993). Conceptualizing, measuring, and managing customer-based brand equity. Journal of Marketing, 57, 1, 1-22.

Lin, C.A. (1993). Cultural differences in message strategies: a comparison between American and Japanese TV commercials. Journal of Advertising Research, 33, 4, pp. 40-8. 
Mendoza, S., Santos Pereira, T.and Mira Godinho, M. (2004). Trademarks as an indicador of innovation and industrialchange. Research Policy, 33, pp. 1385-1404.

Nakata C. and Sivakumar K. (1996). National Culture and New Product Development: An Integrative Review, Journal of Marketing, 60, 61-72.

Pennings J.M. and Harianto F. (1992). The Diffusion of Technological Innovation in the Commercial Banking Industry. Strategic Management Journal 13, 1 pp. 29-46.

Pitta, D.A. and Prevel Katsanis, L. (1995). Understanding brand equity for successful brand extensions. Journal of Consumer Marketing, 12, 4, pp. 51-64.

Ramaprasad, J. and Hasegawa, K. (1990). An analysis of Japanese television commercials. Journalism Quarterly, 67, 4, pp. 1025-1033.

Sethi, R., Smith, D. C. and Park, W. (2001). Cross-Functional Product Development Teams, Creativity, and the Innovativeness of New Consumer Products. Journal of Marketing Research, 37, 73-85.

Shane S.A. (1992). Why do Some Societies Invent more than Others, Journal of Business Venturing, 7, 29-46

Shane S.A. (1993). Cultural Influence on National Rates of Innovation, Journal of Business Venturing, 8, 59-73

Spickett-Jones, G. (2003). Creativity in Product Innovation. Journal of Marketing Management, 19, 699-704.

Steenkamp, J-B E. M., Hofstede, F., Wedel, M. (1999). A Cross-National Investigation into the Individual and National Culture Antecedents of Consumer Innovativeness. Journal of Marketing, 63, 55-69.

Stein M.I. (1953) Creativity and Culture, Journal of Psychology, 36, 311-322

Tversky, A. (1977). Features of similarity. Psychological Review, 84, 327-352. 
Figure 1: Theoretical Model

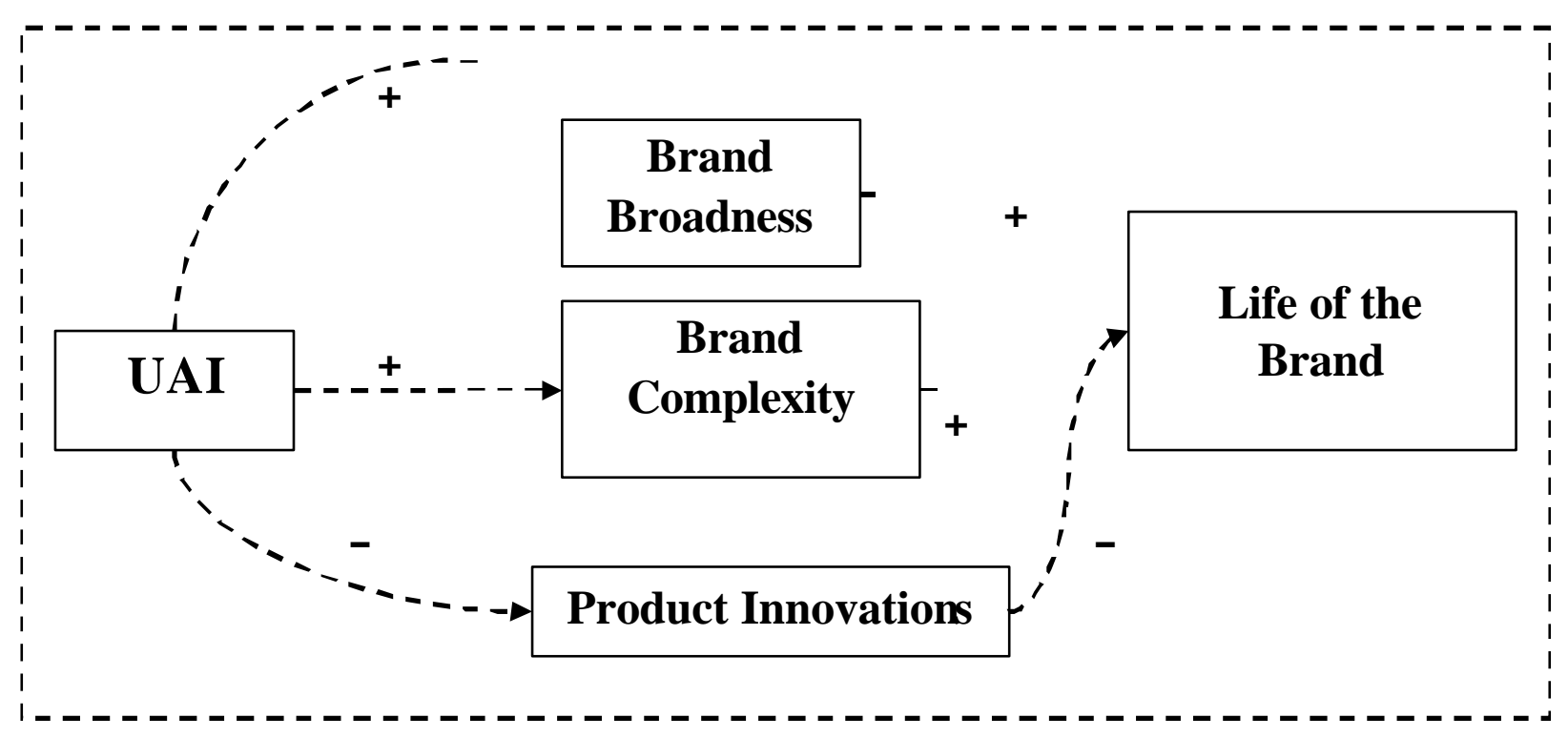


Table 1: Descriptive statistics

\begin{tabular}{lrrrrr}
\hline Variable & Mean & Dev.Stand. & Min & Max \\
\hline Dependent variable & & & & \\
Product innovations & 0.465 & 1.588 & 0 & 8 \\
Brand Broadness & 0.425 & 0.494 & 0 & 1 \\
Brand Complexity & 0.158 & 0.364 & & 1 \\
\hline Independent variable & & & 40 & 92 \\
\hline UAI & 51.090 & 14.108 & 0 & 0.598 \\
Marketing Intesity & 0.095 & 0.066 & 0.047 & 0.187 \\
R\&D Intensity & 0.112 & 0.035 & 100 & $4.70 \mathrm{E}+07$ \\
Fixed Assets & 8237095 & 14400000 & 0 & 123 \\
Firm age & 34.976 & 30.284 & 0 & 9 \\
Trademark Age & 3.842 & 5.651 & 0 & 1 \\
Country dummy 1 & 0.002 & 0.039 & 0 & 1 \\
Country dummy 2 & 0.002 & 0.041 & 0 & 1 \\
Country dummy 3 & 0.001 & 0.032 & 0 & 1 \\
Country dummy 4 & 0.003 & 0.056 & 0 & 1 \\
Country dummy 5 & 0.002 & 0.043 & 0 & 1 \\
Country dummy 6 & 0.004 & 0.063 & 0 & 1 \\
Country dummy 7 & 0.103 & 0.303 & 0 & 1 \\
Country dummy 8 & 0.000 & 0.017 & 0 & 1 \\
Country dummy 9 & 0.021 & 0.142 & 0 & 1 \\
Country dummy 10 & 0.000 & 0.009 & & & \\
\hline \hline
\end{tabular}


Table 2: Logit regression predicting brand broadness and complexity

\begin{tabular}{|l|c|c|c|c|}
\hline $\begin{array}{l}\text { Dependent } \\
\text { Variable }\end{array}$ & \multicolumn{2}{|c|}{ Brand Broadness } & \multicolumn{2}{c|}{ Brand Complexity } \\
\hline Models & $I$ & $I I$ & $I$ & $I I$ \\
\hline UAI & & $7.039^{* *}$ & & $7.631^{* *}$ \\
& & $(0.674)$ & & $(0.746)$ \\
\hline Marketing & $2.953^{* *}$ & $2.865^{* *}$ & $1.889^{* *}$ & $1.837^{* *}$ \\
intensity & $(0.294)$ & $(0.294)$ & $(0.392)$ & $(0.395)$ \\
\hline Fixed Assets & $-0.018^{* *}$ & -0.010 & $0.098^{* *}$ & $0.111^{* *}$ \\
& $(0.007)$ & $(0.007)$ & $(0.011)$ & $(0.012)$ \\
\hline Firm age & $0.130^{* *}$ & $0.059^{* *}$ & $-0.287^{* *}$ & $-0.385^{* *}$ \\
& $(0.025)$ & $(0.026)$ & $(0.037)$ & $(0.039)$ \\
\hline Constant & $-0.758^{* *}$ & $-27.608^{* *}$ & $-2.353^{* *}$ & $-31.468^{* *}$ \\
& $(0.092)$ & $(2.573)$ & $(0.133)$ & $(2.854)$ \\
\hline Dummy country & \multicolumn{5}{|c|}{ YES } \\
\hline Observations & \multicolumn{5}{|c|}{18,213} \\
\hline LogL & $-16,958$ & $-16,901$ & $-10,875$ & $-10,830$ \\
\hline \hline
\end{tabular}

Notes:*.10,**.05 significance levels. Robust heteroskedastic standard errors in parenteses

Table 3: Negative Binomial regression predicting number of new products released

\begin{tabular}{|l|c|c|}
\hline Models & $I$ & $I I$ \\
\hline UAI & & $-8.251^{* *}$ \\
& & $(3.547)$ \\
\hline R\&D intensity & $19.887^{* *}$ & $21.357^{* *}$ \\
& $(3.617)$ & $(3.742)$ \\
\hline Fixed Assets & $0.441^{* *}$ & $0.421^{* *}$ \\
& $(0.071)$ & $(0.074)$ \\
\hline Firm Age & $-0.581^{* *}$ & $-0.458^{* *}$ \\
& $(0.218)$ & $(0.218)$ \\
\hline Constant & $-6.524^{* *}$ & $24.808^{*}$ \\
& $(1.347)$ & $(13.391)$ \\
\hline Dummy country & \multicolumn{2}{|c|}{ YES } \\
\hline Observations & \multicolumn{2}{|c|}{682} \\
\hline LogL & -624.072 & -622.40 \\
\hline
\end{tabular}

Notes:*.10,**.05 significance levels. Robust heteroskedastic standard errors in parenteses 
Table 4: Piecewise-constant hazard rate model, depedent variable trademark hazard of cancellation

\begin{tabular}{lccccc}
\hline Models & $I$ & $I I$ & $I I I$ & $I V$ & $V$ \\
\hline Predicted Brand & & $-0.347^{* *}$ & & & $-0.337^{* *}$ \\
Broadness & & $(0.053)$ & & & $(0.055)$ \\
Predicted Brand & & & $-0.306^{* *}$ & & $-0.260^{* *}$ \\
Complexity & & & $(0.054)$ & & $(0.062)$ \\
Predicted product & & & & $0.343^{* *}$ & $0.266^{* *}$ \\
innovations & & & & $(0.242)$ & $(0.176)$ \\
Marketing & $0.197^{* *}$ & $1.981^{* *}$ & $1.112^{* *}$ & $3.666^{* *}$ & $5.555^{* *}$ \\
Intensity & $(1.045)$ & $(76.157)$ & $(9.502)$ & $(5064.027)$ & $(427,481)$ \\
Fixed Assets & $0.053^{* *}$ & $0.047^{* *}$ & $0.107^{* *}$ & $0.104^{* *}$ & $0.134^{* *}$ \\
& $(0.022)$ & $(0.022)$ & $(0.038)$ & $(0.035)$ & $(0.050)$ \\
Firm Age & $-0.187^{* *}$ & $-0.185^{* *}$ & $-0.383^{* *}$ & $-0.250^{* *}$ & $-0.407^{* *}$ \\
& $(0.051)$ & $(0.051)$ & $(0.046)$ & $(0.045)$ & $(0.046)$ \\
Trademark & $0.048^{* *}$ & $0.046^{* *}$ & $0.048^{* *}$ & $0.048^{* *}$ & $0.046^{* *}$ \\
Age & $(0.015)$ & $(0.014)$ & $(0.015)$ & $(0.014)$ & $(0.014)$ \\
\hline
\end{tabular}

Dummy country YES

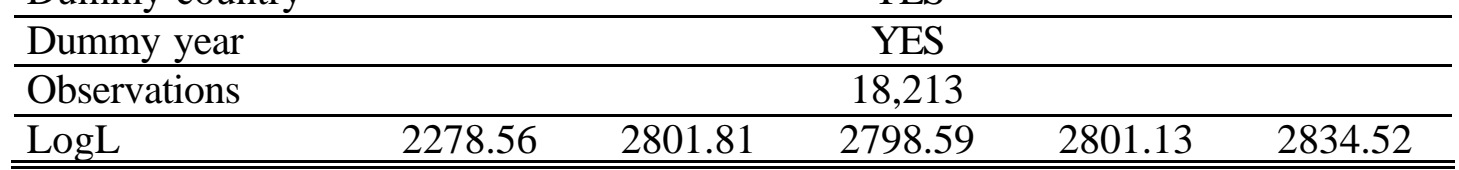

Notes:*.10,**.05 significance levels. Robust heteroskedastic standard errors in parenteses. Coefficients expressed in $\log (\beta)$. 